\title{
PENGARUH BUDAYA ORGANISASI TERHADAP KEBERHASILAN PENERAPAN SISTEM INFORMASI COMPETENCY LEVEL INDEX (CLI)
}

\author{
${ }^{1}$ Syaifullah, ${ }^{2}$ Helen Sonata, ${ }^{3}$ Hasdi Radiles \\ 1,2,3 Program Studi Sistem Informasi, Fakultas Sains dan Teknologi UIN Suska Riau \\ J1. HR Soebrantas KM.18 Panam Pekanbaru - Riau \\ Email: ${ }^{1}$ syaifullah@uin-suska.com, ${ }^{2}$ helensonata96@gmail, \\ ${ }^{3}$ hasdi99@gmail.com
}

\begin{abstract}
ABSTRAK
Penelitian ini membahas tentang pengaruh budaya organisasi terhadap keberhasilan penerapan sistem informasi Competency Level Index (CLI) yang berada di PT. Perkebunan Nusantara V Pekanbaru. Metode yang digunakan yaitu OCAI dan HOT FIT model. OCAI membagikan tipe budaya organisasi menjadi empat yaitu Clan, Adhocrachy, Market dan Hierarchy. HOT FIT model menempatkan tiga komponen sistem informasi yaitu Human, Organization dan Technology. Tujuan penelitian ini adalah untuk mengetahui pengaruh budaya organisasi terhadap keberhasilan penerapan sistem informasi CLI. CLI telah digunakan sejak tahun 2013 namun masih memiliki kendala baik dari segi manusia, organisasi maupun teknologi. Pengumpulan data dilakukan dengan menyebarkan kuesioner kepada 55 responden yang terdiri dari 29 karyawan pada Divisi Perencanaan Stratregis dan 26 karyawan pada Divisi Sumber Daya Manusia. Pengolahan data dilakukan menggunakan Microsoft Excel dan SEM-PLS. Hasil penelitian ini menunjukkan bahwa budaya dominan yang berjalan saat ini adalah market dengan nilai rata-rata 3.092 dan budaya harapan adalah hirarki dengan nilai rata-rata 3.150 serta budaya organisasi berpengaruh terhadap keberhasilan penerapan sistem informasi CLI dengan hasil uji t sebesar 4.435 dan keberhasilan tersebut berada pada level baik dengan nilai 0.769 atau $79 \%$. Hal ini dipengaruhi oleh budaya organisasi yang berorientasi terhadap persaingan dan menciptakan keunggulan yang kompetitif sehingga mencapai target dan mampu menjadi perusahaan yang memiliki kualitas dan daya saing.
\end{abstract}

Kata Kunci: Competency Level Index (CLI), HOT FIT model, OCAI, SEM-PLS.

\section{A. PENDAHULUAN}

Saat ini pemanfaatan sistem informasi menjadi salah satu sumber daya utama dalam komponen organisasi guna mendukung daya saing serta pelayanan perusahaan secara lebih optimal. Salah satu faktor yang mempengaruhi keberhasilan sistem informasi yaitu budaya organisasi (Rahayu et al., 2014). Menurut Cushway dan Lodge (2000) dalam Napitupulu \& Medina (2012) bahwa budaya organisasi merupakan system nilai organisasi yang akan memberikan dampak terhadap karyawan dalam berperilaku dan melakukan pekerjaan, sehingga jika kita ingin mengetahui tingkat perkembangan budaya suatu organisasi maka dapat dilihat dari bagaimana perilaku yang ada di dalam organisasi tersebut. Sebab pengguna merupakan salah satu komponen utama dalam sistem informasi (Lamb \& Kling, 2003)

Menurut Christin (2006) Keberhasilan penerapan sistem informasi akan tercapai jika ada keseimbangan atensi pada teknologi, rencana serta budaya perusahaan dan bagaimana menyatukan ketiga hal tersebut ke dalam proses organisasi. Dengan demikian budaya organisasi perlu dikembangkan sedemikian rupa sehingga mampu menjadi pemersatu dalam menggerakkan anggota organisasi. Hal ini bertujuan agar perilaku organisasi dapat berjalan beriringan dengan tujuan penerapan sistem informasi dalam perusahaan tersebut.
PT. Perkebunan Nusantara (PTPN) V merupakan salah satu perusahaan BUMN (Badan Usaha Milik Negara) yang bergerak di bidang usaha pengelolaan dan pemasaran hasil perkebunan. Untuk meningkatkan mutu dan mencapai tujuan perusahaan, PTPN V telah menerapkan teknologi informasi sebagai media untuk persaingan bisnis, salah satunya yaitu Competency Based Human Resources Management System (CBHRMS) merupakan sistem besar yang menjadikan kompetensi sebagai titik pusatnya yang bertujuan untuk mengembangkan SDM didalamnya agar dapat membangun organisasi yang sukses. Salah satu penerapan CBHRM adalah pengukuran Competency Level Index (CLI). CLI merupakan indeks tingkatan kompetensi perusahaan sebagai Key Performance Indicator (KPI) dalam penerapan Integrated CBHRM System dalam pengelolaan Sumber Daya Manusia.

Sistem ini telah digunakan sejak tahun 2013 dengan jumlah pengguna pada Divisi SDM berjumlah 26 orang dan pada Divisi Perencanaan Strategis berjumlah 29 orang, dimana yang menggunakan sistem ini hanyalah karyawan pimpinan golongan 3A sampai 4D. Secara garis besar sistem ini mengukur soft competency dan hard competency. Pengukuran dibagi menjadi dua jenis yaitu pengukuran terhadap diri sendiri dan pengukuran terhadap kolega. Untuk pengukuran soft competency menggunakan prinsip pengukuran $360^{\circ}$, 
dimana seorang karyawan dinilai oleh atasan, dua orang setingkat dan bawahannya, kecuali untuk karyawan setingkat asisten hanya dinilai oleh atasan dan dua orang rekan kerja setempat. Sedangkan untuk pengukuran hard competency dilakukan secara vertikal sampai dengan atasan dua tingkat diatas karyawan tadi.

Dari hasil pengukuran yang dilakukan menggunakan sistem informasi CLI ini, dapat diketahui tingkat pencapaian karyawan dengan standar kompetensi yang telah diterapkan oleh perusahaan. Sehingga dapat diketahui kompetensi kompetensi apa saja yang perlu dikembangkan agar kinerja karyawan dapat meningkat. Tujuan dibuat CLI ini untuk memudahkan perusahaan dalam mendeskripsikan bagaimana kompetensi seseorang sehingga dapat dilakukan pemetaan karyawan agar lebih bisa meningkatkan mutu perusahaan. Proses pengukuran ini dilakukan setahun sekali oleh Divisi Sumber Daya Manusia.

Berdasarkan hasil wawancara yang telah dilakukan dengan Kepala Sub Bagian TI, Staff Sub Bagian SDM serta Staff Sub Bagian Perencanaan Strategis masih terdapat kendala pada sistem CLI diantaranya dari segi pengguna, organisasi dan teknologi.

Kendala dari faktor pengguna yaitu masih ada beberapa karyawan yang belum menyadari pentingnya sistem CLI ini, hal tersebut dikarenakan kesibukan serta kurangnya kesadaran sehingga menyebabkan karyawan menunda waktu pengisian sistem CLI ini.

Kendala dari faktor organisasi yaitu Selama menerapkan sistem ini, pihak perusahaan belum pernah menerapkan kebijakan adanya sanksi yang akan diterima oleh karyawan apabila terlambat mengisi. Sehingga pihak admin harus menambah waktu pengisian, hal ini tentunya akan mengulur waktu dalam pengambilan keputusan hanya karena beberapa karyawan yang tidak memenuhi aturan

Kendala dari faktor teknologi yaitu pengukuran kompetensi dalam sistem CLI ini hanya diberlakukan untuk karyawan pimpinan saja yakni karyawan pada golongan 3A sampai dengan 4D. Sedangkan untuk karyawan pelaksana yaitu golongan 1A sampai dengan 2D tidak dikenakan pengukuran ini. Sehingga mengakibatkan tidak diketahui bagaimana kompetensi yang dimiliki oleh karyawan pelaksana dikarenakan tidak pernah dilakukan penilaian.

Selain itu, pemberitahuan waktu pengisian CLI cenderung terlambat di informasikan oleh pihak admin sehingga juga menjadi penyebab keterlambatan pengisian dari pihak karyawan mengingat kesibukan karyawan yang juga padat.

Aturan penilaian pada sistem CLI yaitu seorang karyawan saling menilai dan dinilai oleh karyawan lain sesuai yang telah di tentukan oleh pihak admin. Hal ini menimbulkan tidak objektif nya penilaian yang dilakukan dikarenakan karyawan pimpinan tidak selalu mengetahui bagaimana kinerja karyawan lain yang ada pada divisi lain selain divisi yang dipimpinnya.

Dalam penggunaannya proses pengisian sistem CLI dapat dihentikan sementara apabila karyawan ingin menunda pengisian dikarenakan berbagai alasan misalnya karyawan memiliki urusan yang harus didahulukan, data yang telah diisi akan tetap tersimpan. Namun pada kenyataannya, saat akan melanjutkan pengisian karyawan pernah mengalami kehilangan data yang telah diinputkan sehingga harus kembali mengisi data yang telah di isi sebelumnya.

Disamping itu, sistem CLI merupakan sistem berbasis internet sehingga memerlukan koneksi jaringan. Koneksi jaringan yang stabil akan mempercepat pengaksesan sehingga dapat menghasilkan data yang diharapkan. Begitu juga sebaliknya, koneksi jaringan yang tidak stabil akan

menghasilkan data yang tidak sesuai dengan yang diinginkan. Hal ini terjadi pada karyawan ketika sedang melakukan pengisian sistem CLI tibatiba koneksi jaringan menjadi tidak stabil sehingga akan menyulitkan karyawan karena harus mengulang kembali pengisian data.

Berdasarkan penelitian terdahulu yang dilakukan oleh Romi (2011) yang berjudul "Organizational Culture Impact On Information System Success". Penelitian ini menjelaskan model komprehensif yang meneliti bagaimana budaya organisasi dengan berbagai jenisnya (klan, adhokrasi, hierarki, pasar) berdampak pada dimensi keberhasilan sistem informasi (kualitas sistem, kualitas informasi, kualitas layanan, kegunaan, kepuasan pengguna, dan manfaat bersih), untuk mengklasifikasikan berbagai konstruksi budaya organisasi dalam hal dampaknya terhadap keberhasilan sistem informasi.

Selain itu pada penelitian Fauzi (2015) yang berjudul "Pengaruh Budaya Organisasi Terhadap Efektivitas Sistem Informasi". Penelitian ini menggabungkan model yang dapat menggambarkan hubungan antar faktor-faktor budaya yang mempengaruhi efektifitas sistem informasi. Berdasarkan evaluasi yang dilakukan menggunakan metode SEM-PLS, dihasilkan model pengaruh budaya terhadap efektifitas sistem informasi yang terdiri dari 6 konstruk efektifitas yaitu Kualitas Informasi, Kualitas Sistem, Kualitas Layanan, Penggunaan, Kepuasan dan Efektifitas, dan 3 Konstruk dari pengaruh budaya yaitu Clan, Adhocracy dan Hierarchy.

Mengikuti penelitian terdahulu, maka penelitian ini bertujuan untuk mengetahui bagaimana pengaruh budaya organisasi terhadap keberhasilan penerapan sistem informasi CLI. Penelitian ini akan mengukur tingkat keberhasilan penerapan sistem informasi CLI menggunakan metode HOT (Human Organization Technology) Fit Model yang dikembangkan oleh Yusof et al., 
(2006). Sedangkan untuk pemetaan budaya organisasi yang sedang berjalan akan menggunakan Kerangka Culture Value Framework (CVF) dengan instrument Organizational Culture Assesment Instrument (OCAI).

\section{A.1. Budaya Organisasi}

Menurut Wibowo (2010) Dalam setiap organisasi, baik organisasi pemerintahan maupun swasta, budaya selalu mencerminkan organisasi, bagaimana organisasi tersebut dilihat oleh orang lain. Organisasi yang memiliki budaya positif maka akan menunjukkan kesan positif, demikian juga sebaliknya jika budaya organisasi tidak berjalan dengan baik maka akan memberikan kesan yang tidak baik pula. Budaya organisasi lahir melalui proses evolusi dimana ide-ide tercipta dari pendiri organisasi kemudian diwariskan kepada generasi berikutnya. Budaya organisasi tumbuh dan berkembang dengan cara menanamkan melalui proses pembelajaran dan pengalaman.

\section{A.2. Organizational Culture Assigment Instrument (OCAI)}

Organizational Culture Assessment Instrument (OCAI) merupakan instrument dalam menggambarkan profil budaya organisasi. Tujuan OCAI adalah untuk menilai enam dimensi kunci budaya organisasi yang dikaitkan oleh 4 tipe budaya.

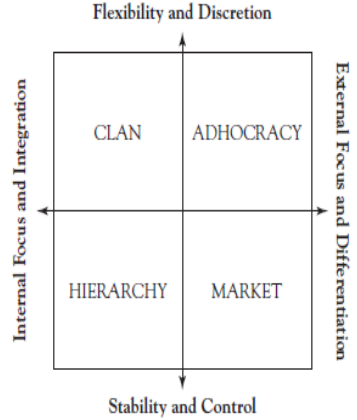

(Sumber: Cameron \& Quinn, 2006)

Gambar 1. Dimesi Budaya Organisasi (Computing Value Framework)

Empat tipe budaya organisasi tersebut adalah budaya hierarchy, budaya market, budaya clan dan budaya adhocracy.Secara lebih jelas hubungan dimensi dan tipe budaya dapat diterangkan oleh Tabel I

Tabel I dimensi dan tipe budaya organisasi

\begin{tabular}{|l|l|l|l|l|}
\hline Dimensi & Clan & Adhocracy & Market & Hierarchy \\
\hline $\begin{array}{l}\text { Karakter } \\
\text { dominan }\end{array}$ & Kekeluargaan & $\begin{array}{l}\text { Dinamis, } \\
\text { kewirausahaan }\end{array}$ & $\begin{array}{l}\text { Orientasi } \\
\text { hasil }\end{array}$ & $\begin{array}{l}\text { Terstruktur, } \\
\text { terkendali }\end{array}$ \\
\hline $\begin{array}{l}\text { Kepemimpinan } \\
\text { organisasi }\end{array}$ & $\begin{array}{l}\text { Mentor, } \\
\text { fasilitator }\end{array}$ & $\begin{array}{l}\text { Inovatif, } \\
\text { pengambilan } \\
\text { resiko }\end{array}$ & $\begin{array}{l}\text { Contoh } \\
\text { yang logis, } \\
\text { agresif }\end{array}$ & Koordinator \\
\hline $\begin{array}{l}\text { Pengelolaan } \\
\text { karyawan }\end{array}$ & Teamwork & $\begin{array}{l}\text { Memberi } \\
\text { kebebasan }\end{array}$ & Kompetitif & Stabilitas \\
\hline $\begin{array}{l}\text { Perekat } \\
\text { organisasi }\end{array}$ & $\begin{array}{l}\text { Kesetiaan, } \\
\text { saling percaya }\end{array}$ & $\begin{array}{l}\text { Komitmen } \\
\text { untuk novasi }\end{array}$ & Agresif & Formal \\
\hline $\begin{array}{l}\text { Penekanan } \\
\text { strategis }\end{array}$ & $\begin{array}{l}\text { Pengembangan, } \\
\text { partisipasi }\end{array}$ & $\begin{array}{l}\text { Penemuan hal } \\
\text { baru }\end{array}$ & $\begin{array}{l}\text { Mencapai } \\
\text { target }\end{array}$ & Stabilitas \\
\hline $\begin{array}{l}\text { Kriteria } \\
\text { keberhasilan }\end{array}$ & $\begin{array}{l}\text { Komitemen } \\
\text { anggota, } \\
\text { kepedulian }\end{array}$ & $\begin{array}{l}\text { Produk baru, } \\
\text { pemimpin } \\
\text { produk }\end{array}$ & $\begin{array}{l}\text { Memimpin } \\
\text { pasar }\end{array}$ & Efisiensi \\
\hline
\end{tabular}

(Sumber: Rangkuti (2013) dalam Umartias (2014)).

\section{A.3. Hubungan Budaya Organisasi dengan Sistem Informasi}

Dalam Dalam paper Claver et al., (2006) yang berjudul "The Performance Of Information System through Organizational Culture" mengemukakan bahwa manusia merupakan komponen khusus dalam sistem informasi, dimana terdapat interaksi antara diri sendiri dengan orang lain yang dikenal sebagai perilaku organisasi serta dapat mempengaruhi keberhasilan sistem informasi.

Budaya informatika dan informasi dibentuk untuk menjelaskan nilai-nilai yang dibagikan oleh anggota perusahaan mengenai IT / IS

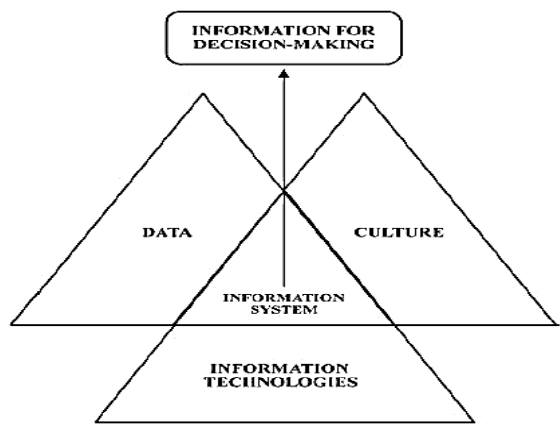

Gambar 1. Pengaruh antara Teknologi Informasi, Sistem Informasi, dan Budaya Organisasi

Gambar 2. menjelaskan bahwa adanya keterkaitan hubungan yang dapat menentukan keberhasilan sistem informasi yakni antara data, teknologi informasi serta budaya yang dapat menjadi instrument keunggulan kompetitif yang utama (Soedjono, 2005). Menurut Rahayu et al., (2014) juga menyatakan bahwa salah satu faktor yang mempengaruhi keberhasilan sistem informasi yaitu budaya organisasi 


\section{A.4. HOT FIT Model}

Teori HOT Fit dikemukakan oleh Yusof et al., (2006) di konferensi Internasional Hawaii Science System ke-39. Model ini merupakan kombinasi dari model kesuksesan sistem informasi dari Delone dan McLean IS Success Model (Delone dan McLean, 2004) dan IT Organization Fit Model (Morton, 1991). Model ini menempatkan komponen penting dalam sistem informasi yakni manusia, organisasi dan teknologi.

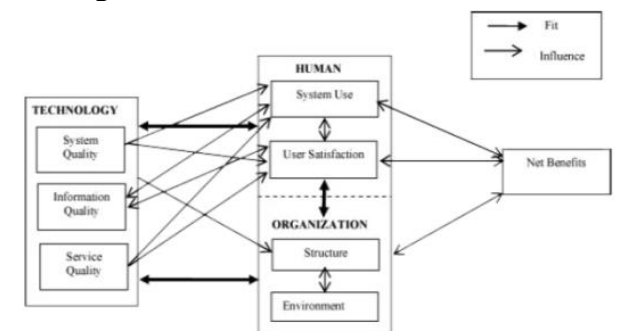

Gambar 2.HOT FIT Model

Dimensi-dimensi ini mempengaruhi antara satu dengan yang lain. Kualitas sistem, kualitas informasi, dan kualitas layanan secara sendiri dan bersama-sama mempengaruhi penggunaan sistem dan kepuasan pengguna. Penggunaan sistem bergantung pada pengetahuan dan pelatihan pengguna. Fit dapat diukur dan dianalis menggunakan jumlah definisi yang diberikan ketiga faktor tersebut. Ketiga factor tersebut berhubungan dengan dimensi relasi dan kesuksesan sistem informasi yaitu Sistem Quality, Information Quality, Service Quality, System Use, User Satisfaction, Structure, Environtmet dan Net Benefit.

\section{A.5. Structural Equation Model (SEM)}

SEM merupakan suatu teknik statistik yang mampu menganalisis pola hubungan yang terdapat pada konstrak laten yang satu dengan yang lainnya, konstrak laten dengan indikatornya serta kesalahan pengukuran yang dilakukan secara langsung. SEM merupakan keluarga statistik multivariate dependent. SEM memungkinkan dilakukannya analisis diantara beberapa variabel dependent dan independent secara langsung (Hair at al, 1995 dalam Yamin \& Kurniawan, 2009).

\section{A.6. Analisis Part Least Square (PLS)}

PLS merupakan salah satu metode statistika SEM berbasis varian yang didesain untuk menyelesaikan regresi berganda ketika terjadi permasalahan spesifik pada data, seperti ukuran sampel PENELITIAN kecil, adanya data yang hilang (missing values) dan multikolinearitas antar prediktor sehingga meningkatkan standart error dari koefesien yang diestimasi.

PLS mengukur varian antara dua atau lebih blok variabel dan menghasilkan seperangkat variabel dan menghasilkan seperangkat variabel yang optimal bagi varian maksimum dengan menggunakan beberapa dimensi (Jogiyanto, 2015).

\section{B. METODOLOGI PENELITIAN}

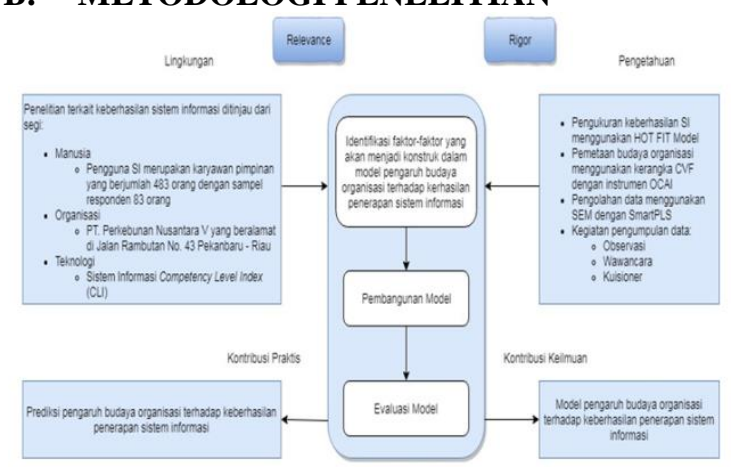

Gambar 3. Alur Metodologi Penelitian

Mengacu pada kerangka penelitian yang dilakukan oleh Hevner et al., (2004) dan Fauzi (2015), penelitian ini juga akan membangun sebuah model yang didasarkan pada basis pengetahuan dan lingkungan. Dimana konsep utama dari segi pengetahuan yaitu keberhasilan sistem informasi CLI yang dilihat berdasarkan komponen manusia, teknologi dan organisasi dengan pengukuran menggunakan HOT FIT model serta melakukan pemetaan budaya organisasi yang sedang berjalan akan menggunakan Kerangka Culture Value Framework (CVF) dengan instrument Organizational Culture Assesment Instrument (OCAI).

\section{ANALISA DAN HASIL}

Berikut merupakan hasil analisa dan statistik pada penelitian pengaruh budaya organisasi terhadap keberhasilan sistem informasi CLI:

\section{C.1. Budaya Organisasi}

Analisis budaya organisasi dilakukan menggunakan CVF (Competing Values Framework) yang bertujuan agar dapat memberikan gambaran mengenai peran nilai-nilai yang ada didalam budaya organisasi yang mencerminkan karakter organisasi. Tabel II Pemetaan Budaya Organisasi

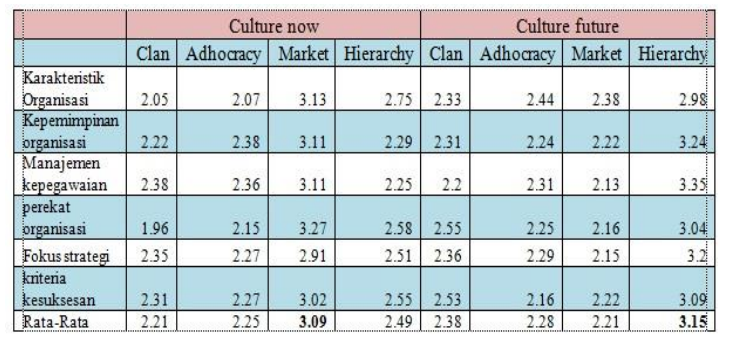

Tabel diatas menunjukkan karakteristik yang paling menonjol dalam sebuah lingkungan budaya organisasi 
Tabel III Peringkat Karakteristik Budaya

\begin{tabular}{|l|r|r|l|r|}
\hline & $\begin{array}{l}\text { Present } \\
\text { Culture }\end{array}$ & \multicolumn{1}{c|}{ Peringkat } & $\begin{array}{l}\text { Future } \\
\text { Culture }\end{array}$ & \multicolumn{1}{c|}{ Peringkat } \\
\hline Clan & 2.21 & 4 & 2.38 & 2 \\
\hline Adhocracy & 2.25 & 3 & 2.28 & 3 \\
\hline Market & 3.09 & 1 & 2.21 & 4 \\
\hline Hierarchy & 2.49 & 2 & 3.15 & 1 \\
\hline
\end{tabular}

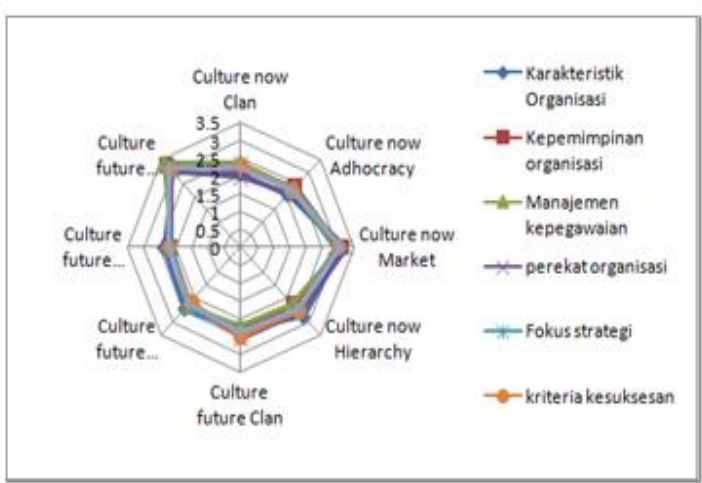

Gambar 5. Diagram Radar Budaya Dominan Sekarang dan Diharapkan

Dari gambar di atas data dilihat budaya yang sedang berjalan adalah market sedangkan budaya yang diharapkan adalah hirarki.

\section{C.2. Pengaruh Budaya Organisasi Terhadap Keberhasilan Sistem Informasi CLI}

Penelitian ini melakukan analisis data yang diperoleh dari kuesioner dengan menggunakan metode SEM-PLS. Evaluasi terhadap model yang dibangun dilakukan dengan menggunakan perangkat lunak yaitu Smart PLS 3.0 Evaluasi tersebut terdiri dari mengevaluasi Outer Model serta mengevaluasi Inner Model. Tahap pengolahan data dari diagram jalur yang telah dirancang menggunakan SmartPLS 3.0 adalah sebagai berikut.

\section{C.2.1 Evaluasi Model pengukuran (Outer Model)}

Evaluasi Outer Model dengan indikator refleksif dinilai melalui Convergent Validity dan Discriminant Validity dari indikator pembentuk konstruk laten dan Composite Reability serta Cronbach's Alpha untuk blok indikatornya

a. Uji Validitas

Pengujian validitas dilakukan untuk mengetahui apakah instrument penelitian yang digunakan adalah valid atau tidak
1) Uji Convergent Validity

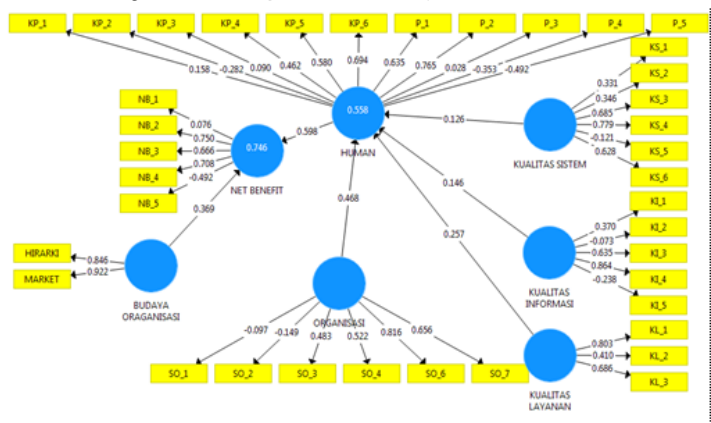

Gambar 6. Convergent Validity Model Keseluruhan

Dari diagram jalur tersebut, lakukan estimasi ulang untuk melihat apakah nilai loading telah memenuhi criteria dari convergent validity, dimana data dapat dinyatakan diterima apabila nilainya $>0.50$.

\section{2) Discriminant Validity}

Kriteria kedua yang digunakan dalam penilaian outer model adalah dengan discriminant validity cara mengukur outer model dengan discriminant validity diantaranya adalah berdasarkan nilai cross loading dan berdasarkan nilai Average Variance Extracted (AVE).

TABEL IV AVERAGE VARIANCE EXTRACTED (AVE)

\begin{tabular}{|c|c|}
\hline & AVE \\
\hline Budaya Organisasi & 0.785 \\
\hline Human & 0.513 \\
\hline Kualitas Informasi & 0.616 \\
\hline Kualitas Layanan & 0.608 \\
\hline Kualitas Sistem & 0.508 \\
\hline Net Benefit & 0.520 \\
\hline Organisasi & 0.531 \\
\hline
\end{tabular}

b. Uji Reliabilitas

Untuk mengukur reliabilitas suatu konstruk dengan indikator formatif dapat dilakukan dengan dua cara yaitu dengan composite reliability dan cronbach alpha. Namun penggunaan cronbach alpha untuk menguji reliabilitas konstruk akan memberikan nilai yang lebih rendah (under estimate) sehingga lebih disarankan untuk menggunakan composite reliability dalam menguji reliabilitas konstruk.

Tabel V Composite Reliability 


\begin{tabular}{|c|c|}
\hline & $\begin{array}{c}\text { Composite } \\
\text { Reliability }\end{array}$ \\
\hline Budaya Organisasi & 0.879 \\
\hline Human & 0.808 \\
\hline Kualitas Informasi & 0.755 \\
\hline Kualitas Layanan & 0.753 \\
\hline Kualitas Sistem & 0.755 \\
\hline Net Benefit & 0.764 \\
\hline Organisasi & 0.769 \\
\hline
\end{tabular}

Hasil diatas menunjukkan bahwa nilai Composite Reliability dari setiap konstruk $>0.60$, dari hasil tersebut dapat dibuktikan bahwa semua konstruk pada model yang diestimasi memenuhi kriteria Discriminant Validity.

\section{C.2.2 Evaluasi Model Struktural (Inner Model)}

Pengujian model structural dapat dilakukan melalui dua tahapan, yaitu uji kelayakan model dan uji signifikan jalur. Model structural menggambarkan hubungan antar variabel laten

a. Uji R-square

Uji yang dilakukan untuk menilai model structural adalah dimulai dengan melihat R-Square untuk kekuatan prediksi dari model structural. Nilai R-Square $0.75,0.50$ dan 0.25 dapat disimpulkan bahwa model dikatakan kuat, moderate dan lemah (Ghazali. 2015)

Tabel VI Nilai R-Square

\begin{tabular}{|l|l|}
\hline & R-Square \\
\hline Human & 0.513 \\
\hline Net Benefit & 0.769 \\
\hline
\end{tabular}

\section{C.3. Pengujian Hipotesis}

Uji kedua yang dapat dilakukan dapat untuk menilai model structural adalah dengan melihat nilai koefisien parameter dan nilai siginfikasi t statistik. Pengujian $\mathrm{t}$ statistic dilakukan untuk mengetahui apakah hipotesis pada model dapat diterima atau ditolak, apabila hasil dari uji t statistic lebih besar dari t tabel (1.96) maka hipotesis dapat diterima, namun bila t statistic lebih kecil dari t tabel (1.96) maka hipotesis ditolak.

Tabel VII Nilai Path Coefficient

\begin{tabular}{|l|c|c|c|c|}
\hline & $\begin{array}{c}\text { Original } \\
\text { Sample } \\
(\mathrm{O})\end{array}$ & $\begin{array}{c}\text { Sample } \\
\text { Mean } \\
(\mathrm{M})\end{array}$ & $\begin{array}{c}\text { Standard } \\
\text { Deviation } \\
(\text { STDEV })\end{array}$ & $\begin{array}{c}\text { T Statistic } \\
(\text { (O/STERR })\end{array}$ \\
\hline Budaya Organisasi $\rightarrow$ Net Benefit & 0.389 & 0.378 & 0.081 & 4.182 \\
\hline Human $\rightarrow$ Net Benefit & 0.597 & 0.611 & 0.070 & 8.583 \\
\hline Kualitas Informasi $\rightarrow$ Human & 0.075 & 0.086 & 0.122 & 0.616 \\
\hline Kualitas Layanan $\rightarrow$ Human & 0.222 & 0.214 & 0.093 & 2.389 \\
\hline Kualitas Sistem $\rightarrow$ Human & 0.265 & 0.275 & 0.115 & 2.315 \\
\hline Organisasi $\rightarrow$ Human & 0.461 & 0.449 & 0.089 & 5.165 \\
\hline
\end{tabular}

\section{C.4. Hasil Pengujian Hipotesis}

Menurut Hartono (2008) dalam Jogiyanto dan Abdillah (2009) menjelaskan bahwa ukuran signifikasi keterdukungan hipotesis dapat digunakan perbandingan nilai t-table dan t-statistic. Jika tstatistik lebih tinggi dibandingkan nilai t-table, berarti hipotesis diterima. Dalam hal ini dilakukan metode bootsrap terhadap sampel. Pengujian dalam bootstrap juga dimaksudkan untuk meminimalkan masalah ketidaknormalan data penelitian. Hasil pengujian dengan menggunakan bootsratping dari analisis PLS yakni sebagai berikut.

Tabel VIII Pengujian Hipotesis

\begin{tabular}{|l|l|l|c|l|}
\hline Hipotesis & \multicolumn{2}{|c|}{ Jalur } & T-Value (t) & Hasil Pengujian \\
\hline & Dari & Ke & & \\
\hline H1 & KI & PS & 2.864 & Diterima \\
\hline H2 & KI & KP & 0.590 & Ditolak \\
\hline H3 & KS & PS & 1.070 & Ditolak \\
\hline H4 & KS & KP & 2.328 & Diterima \\
\hline H5 & KL & PS & 0.610 & Ditolak \\
\hline H6 & KL & KP & 1.686 & Ditolak \\
\hline H7 & KP & PS & 3.902 & Diterima \\
\hline H8 & PS & NB & 5.978 & Diterima \\
\hline H9 & KP & NB & 1.807 & Ditolak \\
\hline H10 & SO & NB & 0.346 & Ditolak \\
\hline H11 & BO & NB & 4.435 & Diterima \\
\hline
\end{tabular}

Model hipotesis yang dikembangkan untuk pengaruh budaya organisasi terhadap keberhasilan sistem CLI adalah sebagai berikut:

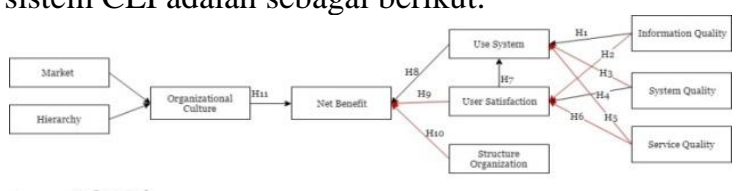

Gambar 7. Hasil Uji Hipotesis

\section{C.5. Pembahasan dan Hasil} berikut:

Uji Hasil data yang telah diolah yaitu sebagai

\section{Budaya Organisasi}

Penilaian budaya organisasi yang dilakukan menggunakan CVF (Computing Value Framework) menggunakan 4 indikator yaitu clan, adokrasi, market dan hirarki. Berdasarkan hasil kuesioner maka didapatkan budaya organisasi yang berjalan adalah market dengan nilai rata-rata 3.092 dan budaya yang diharapkan adalah hirarki dengan nilai rata-rata 3.150

2. Kualitas Informasi Terhadap Penggunaan Sistem

Berdasarkan hasil Pengujian Hipotesis 1 menunjukkan bahwa hubungan variabel kualitas iinformasi dengan penggunaan sistem menunjukkan nilai $\mathrm{T}>\mathrm{T}$-tabel (1.96) sehingga kualitas informasi berpengaruh terhadap tingkat penggunaan sistem, semakin tinggi kualitas informasi maka semakin tinggi pula penggunaan sistem tersebut. Kedua indikator tersebut saling berpengaruh disebabkan karena informasi yang diberikan oleh sistem utuh dan akurat serta dapat di pertanggungjawabkan oleh perusahaan. Sistem CLI juga digunakan sebagai sistem pendukung 
pengambil keputusan, maka kualitas informasi sangat berpengaruh terhadap penggunaan sistem

3. Kualitas Informasi Terhadap Kepuasan Pengguna

Berdasarkan hasil pengujian Hipotesis 2 menunjukkan bahwa hubungan variabel kualitas informasi dengan kepuasan pengguna menunjukkan nilai $\mathrm{T}<\mathrm{T}$-tabel (1.96). Kedua indikator tersebut tidak salingdikarenakan saat koneksi jaringan yang tidak stabil menghasilkan data dan informasi yang tidak sesuai dengan yang diinginkan. Hal ini terjadi pada karyawan ketika sedang melakukan pengisian sistem CLI tiba-tiba koneksi jaringan menjadi tidak stabil sehingga akan menyulitkan karyawan karena harus mengulang kembali pengisian data

4. Kualitas Sistem Terhadap Penggunaan Sistem

Berdasarkan hasil pengujian Hipotesis 3 menunjukkan bahwa hubungan variabel kualitas sistem dengan penggunaan sistem menunjukkan nilai $\mathrm{T}<\mathrm{T}$-tabel (1.96). Kedua indikator tersebut tidak saling berpengaruh disebabkan karyawan menilai dan dinilai oleh karyawan lain sesuai divisi yang telah dipilih oleh pihak admin. Sehingga menyebabkan tidak objektif nya penilaian yang dilakukan karena tidak semua karyawan memahami kinerja karyawan yang ada dalam divisi lain serta sistem ini hanya mengukur kompetensi yang dimiliki oleh karyawan pimpinan, sedangkan untuk karyawan pelaksana tidak dikenakan pengukuran ini, sehingga menyebabkan perusahaan tidak mendapatkan hasil yang optimal

\section{Kualitas Sistem Terhadap Kepuasan Pengguna}

Berdasarkan hasil pengujian Hipotesis 4 menunjukkan bahwa hubungan variabel kualitas sistem dengan kepuasan pengguna menunjukkan nilai $\mathrm{T}>\mathrm{T}$-tabel (1.96). Semakin tinggi kualitas sistem maka semakin tinggi pula kepuasan pengguna terhadap sistem tersebut. Kedua indikator tersebut saling berpengaruh disebabkan sistem mudah untuk digunakan, keamanan data terjamin karena setiap user memiliki hak akses masing-masing, sehingga rahasia informasi yang telah dimasukkan akan tetap terjaga. Hal tersebut menjadi faktor berpengaruhnya kualitas sistem terhadap kepuasan pengguna

\section{Kualitas Layanan Terhadap Penggunaan} Sistem

Berdasarkan hasil pengujian Hipotesis 5 menunjukkan bahwa hubungan variabel kualitas layanan dengan penggunaan sistem menunjukkan nilai $\mathrm{T}<\mathrm{T}$-tabel (1.96). Kedua indikator tersebut tidak saling berpengaruh disebabkan dikarenakan pemberitahuan waktu pengisian CLI cenderung terlambat oleh pihak admin. Hal ini menjadi faktor kualitas layanan tidak berpengaruh terhadap penggunaan sistem

\section{Kualitas Layanan Terhadap Kepuasan Pengguna}

Berdasarkan hasil pengujian Hipotesis 6 menunjukkan bahwa hubungan variabel kualitas layanan dengan kepuasan pengguna menunjukkan nilai $\mathrm{T}<\mathrm{T}$-tabel (1.96). Kedua indikator tersebut tidak saling berpengaruh dikarenakan disebabkan pengisian CLI dapat dihentikan sementara lalu dapat dilanjutkan kembali, namun saat akan melanjutkan pengisian, karyawan pernah mengalami kehilangan data nya sehingga harus mengulang dari awal. Sehingga data dan informasi yang telah dimasukkan tidak lengkap

\section{Kepuasan Pengguna Terhadap Penggunaan} Sistem

Berdasarkan hasil pengujian Hipotesis 7 menunjukkan bahwa hubungan variabel kepuasan pengguna dengan penggunaan sistem menunjukkan nilai $\mathrm{T}>\mathrm{T}$-tabel (1.96). Semakin meningkat kepuasan pengguna maka akan semakin tinggi pula penggunaan sistem tersebut. Kedua indikator tersebut saling berpengaruh dikarenakan tingkat penggunaan sistem yang tinggi serta cukupnya pengetahuan karyawan mengenai sistem ini dikarenakan sistem juga mudah untuk dipahami.

\section{Penggunaan Sistem Terhadap Net Benefit}

Berdasarkan hasil pengujian Hipotesis 8 menunjukkan bahwa hubungan variabel penggunaan sistem dengan net benefit menunjukkan nilai $\mathrm{T}>\mathrm{T}$-tabel (1.96). Semakin tinggi penggunaan sistem maka akan semakin tinggi pula net benefit yang didapatkan. Kedua indikator tersebut saling berpengaruh dikarenakan sistem telah berjalan sesuai dengan fungsi nya yakni dapat membantu perusahaan dalam pengambilan keputusan sehingga memberikan hasil yang positif pula untuk perusahaan

\section{Kepuasan Pengguna Terhadap Net Benefit}

Berdasarkan hasil pengujian Hipotesis 9 menunjukkan bahwa hubungan variabel kepuasan pengguna dengan net benefit menunjukkan nilai $\mathrm{T}$ $<$ T-tabel (1.96). Kedua indikator tersebut tidak saling berpengaruh dikarenakan masih ada karyawan yang mengabaikan dan cenderung terlambat mengisi sehingga akan menunda pula proses pengambilan keputusan. Hal ini mempengaruhi efisiensi pekerjaan serta tujuan perusahaan.

\section{Organisasi Terhadap Net Benefit}

Berdasarkan hasil pengujian Hipotesis 10 menunjukkan bahwa hubungan variabel organisasi dengan net benefit menunjukkan nilai $\mathrm{T}<\mathrm{T}$-tabel 
(1.96). Kedua indikator tersebut tidak saling berpengaruh karena belum adanya kebijakan dari perusahaan adanya sanksi untuk karyawan yang cenderung terlambat melakukan

pengisian CLI yang mengharuskan pihak admin menambah waktu pengisian. Hal ini mengakibatkan penundaan dalam pengambilan keputusan serta pencapaian tujuan yang kurang efektif

\section{Budaya Organisasi Terhadap Net Benefit}

Berdasarkan Berdasarkan hasil pengujian Hipotesis 11 menunjukkan bahwa hubungan variabel budaya organisasi dengan net benefit nilai $\mathrm{t}$ statistic > t tabel (1.96) berada pada level baik 0.769 atau 76\%. Dimana budaya organisasi yang mempengaruhi net benefit atau keberhasilan sistem informasi CLI adalah budaya dominan yang berjalan saat ini yaitu budaya market yaitu tipe budaya yang berorientasi pada hasil, dimana nilainilai yang dianggap penting adalah kompetensi dan produktivitas. Tipe budaya yang digambarkan dengan penguasaan pasar, dengan gaya organisasi cenderung megutamakan daya saing yang gesit dan suka kerja keras. Sedangkan untuk budaya organisasi yang diharapkan adalah budaya hierarchy. Dimana Hierarchy lebih berorientasi pada perusahaan yang formal dan terstruktur, sehingga setiap aktivitas harus sesuai dengan deskripsi dan intruksi kerja. Hal ini bertujuan untuk mencapai target sesuai dengan yang dikehendaki oleh perusahaan

\section{KESIMPULAN DAN SARAN \\ D.1. Kesimpulan}

Berdasarkan uraian dan pembahasan seluruh

bab, maka dapat disimpulkan hasil penelitian sebagai berikut

1. Budaya organisasi yang sedang berjalan adalah budaya organisasi market dengan nilai rata-rata 3.092. Sedangkan budaya organisasi yang di harapkan adalah hirarki dengan nilai rata-rata 3.150 .

2. Budaya organisasi berpengaruh terhadap tingkat keberhasilan penerapan sistem informasi CLI. Berdasarkan hasil uji t statistic di dapatkan hasil 4.435 dimana t statistic lebih besar dari t tabel (1.96) serta tingkat keberhasilan berada pada level baik dengan nilai 0.769 atau $79 \%$. Hal ini dikarenakan variabel kualitas sistem dan kualitas informasi berpengaruh positif terhadap variabel Human. Dimana variabel Human dan budaya organisasi berpengaruh positif terhadap net benefit.

\section{D.2. Saran}

Berdasarkan hasil analisa dan pembahasan sebelumnya, maka beberapa saran yang dirasa perlu untuk dilakukan, antara lain sebagai berikut:
1. Penelitian ini dapat dilanjutkan sampai pada tahap rekomendasi. Sehingga masih dapat dlanjutkan oleh penelitian berikutnya dengan memberikan rekomendasi dan mengukur keberhasilan penerapan sistem informasi secara kompleks dengan indikator lengkap.

2. Data yang sedikit dan variabel yang banyak menjadi kekurangan dalam penelitian ini sehingga menghasilkan uji hipotesis yang rendah, sehingga diharapkan untuk penelitian selanjutnya lebih memprediksi pengaruh antara budaya organisasi dan keberhasilan sistem informasi dengan data responden diatas 100

\section{REFERENSI}

[1] Andika. Bayu S., dan Izzati Muhimmah. "Evaluasi Faktor-Faktor Kesuksesan Implementasi Sistem Informasi manajemen Rumah Sakit di PKU Muhammadiyah Sruweng dengan Menggunakan Metode HOT Fit". Seminar Nasional Informatika Medis. Hal 78-86. November. 2013.

[2] Cameron, Kim. S., dan Robert E. Quinn "Diagnosing and Changing Organizational Culture". Jossey Bass, San Francisco.

[3] Chatab, Nevizond. "Perilaku Budaya Organisasi". Alfabeta, Bandung. 2007.

[4] Christin. "Peran Budaya Organisasi Dalam Mendukung Keberhasilan Implementasi Knowledge Management Systems". Vol. 10 No. 1, hal 26-40. 2006

[5] Claver, Enrique. et al., "The Performance Of Information Systems Through Organizational Culture". Performance of Information Systems. Hal 247-259. 2006

[6] Fauzi, C. "Pengaruh Budaya Organisasi Terhadap Efektivitas Sistem Informasi". Seminar Nasional Aplikasi Teknologi Informasi. Hal. 1-8. Yogyakarta. 2015

[7] Ghozali, Imam. "Structural Equation Modeling : Metode Alternatif Dengan Partial Least Squares (PLS)". Universitas Diponegoro, Semarang. 2014

[8] Hevner, Alan R., et al., "Design Science In Information System Research". MIS Quarterly, Vol. 28 No. 1, hal. 75-105. 2004

[9] Jogiyanto. "Partial Least Square (PLS) Alternatif Structural Equation Modelling (SEM) Dalam Penelitian Bisnis". Andi Offset, Yogyakarta. 2015

[10] Kodarisman, Raden. dan Eko Nugroho. "Evaluasi Penerapan Sistem Informasi Manajemen Kepegawaian ( SIMPEG ) di Pemerintah Kota Bogor". Vol. 2 No. 2, hal. 2432. 2013

[11] Krisbiantoro, Dwi, et al. "Evaluasi Keberhasilan Implementasi Sistem Informasi Dengan Pendekatan Hot Fit Model ( Studi Kasus: Perpustakaan STMIK AMIKOM 
Purwokerto)". Konferensi Nasional Sistem \& Informatika, hal 9-10. 2015

[12] Lamb, Roberta. dan Rob Kling. "Reconceptualizing Users As Social Actors In Information Systems Research". MIS Quarterly. Vol. 27 No. 2, hal. 197-236. 2003

[13] Napitupulu, Togar A. dan Desmi Avicena Medina. "Keberhasilan Pengembangan EGovernment Budaya Organisasi dan eGovernment". Binus Business Review:382391, Vol. 3 No. 1, hal. 382-391. 2012

[14] Rahayu, Siti Kurnia. et al. "Analisis Budaya Organisasi Pada Pengembangan Sistem Infomasi di UNIKOM". Majalah Ilmiah UNIKOM, Vol. 12 No. 2, hal 203-210. 2014

[15] Robbins, Stephen P. "Organizational Behaviour". Pearson Prentice Hall, New Jersey. 2007

[16] Romi, Ismail M. "Organizational Culture Impact on Information Systems Success". Proceeding 1st Computer Science And
Software Tehniques In 2011 Computer Science And Software Tehniques In 2011, hal 43-50. 2011

[17] Umartias, M. "Pemetaan Budaya Organisasi Menggunakan Organizational Culture Assessment Instrument (OCAI) Pada PT Kereta Api Indonesia Daerah Operasional 4 Semarang". 2014

[18] Wibowo. "Budaya Organisasi: Sebuah Kebutuhan Untuk Meningkatkan Kinerja Jangka Panjang". RajaGrafindo, Jakarta. 2010

[19] Yamin, Sofyan. dan Heri Kurniawan. "Structural Equation Modeling: Belajar Lebih Mudah Teknik Analisis Data Kuisioner dengan Lisrel-PLS". Salemba Infotek, Jakarta. 2009

[20] Yusof, M. Mohd. et al. "Towards a Framework for Health Information Systems Evaluation". Proceeding of the 39th Hawaii International Conference on System Sciences, (0-76952507-5/06/\$20.00(C)), hal 1-10. 2006. 